\title{
Estudo De Prevalência De Lesões De Pele Na Campanha Do Dia Nacional De Combate Ao Câncer Da Pele Entre Os Anos De 2009 A 2013 Na Cidade Do Rio Grande
}

\author{
Miranda, B.S.; Lorenzi, C.; Conejo, V.S.; Danielski, T.P.; Rodrigues, O.; \\ Apresentador: Bruna da Silva Miranda
}

\section{Resumo}

Introdução: A exposição ao sol inadequada é um dos principais fatores responsáveis pelo câncer de maior incidência no Brasil: o câncer de pele não melanoma. Se detectado precocemente, essas neoplasias apresentam elevado percentual de cura. A Sociedade Brasileira de Dermatologia (SBD) realiza anualmente a Campanha do Dia Nacional de Combate ao Câncer da Pele, tendo como foco a orientação sobre a prevenção, o exame da pele e o diagnóstico precoce da neoplasia. Em Rio Grande, as campanhas realizadas de 2005 a 2013 corroboraram para o entendimento da forma como essas lesões se expressam nessa população. Objetivos: Apresentar taxas de prevalência de lesões de pele suspeitas de neoplasia que foram excisadas cirurgicamente entre as campanhas de 2009 e 2013 na cidade do Rio Grande e tiveram diagnóstico firmado pelo Centro Integrado de Patologia (CIP), correlacionando as lesões encontradas com os fatores de risco e proteção dos pacientes. Método: Estudo transversal em que se utilizou o banco de dados das campanhas dos últimos 5 anos (2009-2013) como fonte de análise. Foram estudados apenas informações de pacientes que fizeram o procedimento cirúrgico de retirada das lesões suspeitas, por aplicação de questionário e análise, juntamente com os resultados dos laudos anatomopatológicos disponibilizados pelo CIP. Resultados: A revisão resultou da análise de 274 pacientes $(\mathrm{n}=274)$, sendo 60 do ano de 2009, 50 de 2010, 56 de 2011, 46 de 2012 e 72 pacientes do ano de 2013. As prevalências encontradas nas últimas quatro campanhas foram: 132 casos de carcinoma basocelular, 69 casos de ceratose, 55 casos de carcinoma epidermóide, 36 casos de nevo, 11 casos de processo inflamatório, 8 casos de fibroma, 3 casos de melanoma, 3 casos de hemangioma, 1 caso de hidroadenoma, 2 caso de hiperplasia, 1 caso de pele normal, e 1 caso de siringoma de células claras. Estatisticamente, a prevalência de casos malignos (carcinoma basocelular, carcinoma epidermóide e melanoma) foi bem maior que os benignos, sendo 69,34\% neoplasias malignas. Conclusões: Devido à alta prevalência do câncer da pele na população surge a necessidade de orientar cada vez mais sobre a exposição solar e seus riscos. Serve ainda como incentivo para que as Campanhas de Prevenção ao Câncer da Pele sejam estimuladas e mais difundidas, para tentar alcançar um número ainda maior de pacientes, realizar o diagnóstico e, conseqüentemente, instaurar um tratamento mais precoce.

\section{Referência:}

Miranda, B.S.; Lorenzi, C.; Conejo, V.S.; Danielski, T.P.; Rodrigues, O.;. Estudo De Prevalência De Lesões De Pele Na Campanha Do Dia Nacional De Combate Ao Câncer Da Pele Entre Os Anos De 2009 A 2013 Na Cidade Do Rio Grande. In: II Congresso Brasileiro de Medicina Hospitalar - II CBMH [= Blucher Medical Proceedings, vol.1, num.5] São Paulo: Editora Blucher, 2014. p.55

DOI 10.5151/medpro-II-cbmh-050 